\title{
GUIDELINES ON MANAGEMENT OF HUMAN INFECTION WITH THE NOVEL VIRUS INFLUENZA A (H1N1) - A REPORT FROM THE HOSPITAL DAS CLÍNICAS OF THE UNIVERSITY OF SÃO PAULO
}

\author{
Ludhmila Abrahao Hajjar,, Denise Schout," Filomena Regina Barbosa Gomes \\ Galas, ${ }^{\mathrm{I}}$ David Everson Uip, ${ }^{\mathrm{III}}$ Anna Sara Shafferman Levin, ${ }^{\text {IV }}$ Helio Hehl Caiaffa \\ Filho, ${ }^{\mathrm{V}}$ Pedro Takanori Sakane, ${ }^{\mathrm{VI}}$ Carlos Alberto Suslik, ${ }^{\mathrm{VII}}$ Jose Manoel de \\ Camargo Teixeira, ${ }^{\mathrm{VIII}}$ Eloisa Bonfa, ${ }^{\mathrm{IX}}$ Antonio Alci Barone, ${ }^{\mathrm{IV}}$ Milton de Arruda \\ Martins, ${ }^{\mathrm{IX}}$ Marcos Boulos, ${ }^{\mathrm{X}}$ and Jose Otavio Costa Auler Jr. ${ }^{\mathrm{XI}}$
}

doi: $10.1590 / \mathbf{S 1 8 0 7 - 5 9 3 2 2 0 0 9 0 0 1 0 0 0 0 1 3}$

Hajjar LA, Schout D, Galas FRBG, Uip DE, Levin ASS, Caiaffa-Filho HH et al. Guidelines on management of human infection with the novel virus influenza A (H1N1) - A report from the Hospital das Clínicas of the University of São Paulo. Clinics. 2009;64(10):1015-24.

The pandemic novel influenza A (H1N1) infection was considered widespread in Brazil on July, 2009. Since then, 9.249 cases were confirmed in Brazil, most of them concentrated in São Paulo. The Hospital das Clínicas of the University of São Paulo is a reference center for H1N1 cases in São Paulo. The purpose of this review is to analyze the evidence concerning diagnosis, prevention, and treatment of novel influenza A (H1N1) infection. In addition, we propose guidelines for the management of this pandemic emphasizing Hospital das Clínicas "bundles” for the control of the pandemic novel influenza A (H1N1).

KEYWORDS: Review; Hospital das Clínicas; Pandemic; Swine Origin Infection Virus.

\section{INTRODUCTION}

In April 2009, the first two cases of human infection with a novel influenza A (H1N1) virus were reported in the United States. ${ }^{1}$ During the same period, an outbreak of respiratory infection was reported in Mexico. ${ }^{2}$ The virus was found to be an $\mathrm{H} 1 \mathrm{~N} 1$ virus that was antigenically and genetically unrelated to human seasonal influenza viruses and genetically related to viruses known to circulate in swine. ${ }^{3}$ In the ensuing

\footnotetext{
I Department of Anesthesiology, InCor-Heart Institute and Instituto do Câncer do Estado de São Paulo - Hospital das Clínicas da Faculdade de Medicina da Universidade de São Paulo - São Paulo/SP, Brazil.

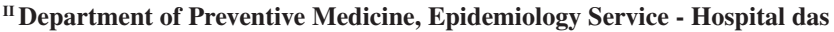
Clínicas da Faculdade de Medicina da Universidade de São Paulo - São Paulo/SP, Brazil.

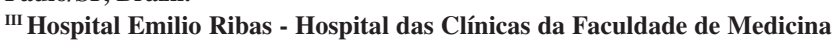
da Universidade de São Paulo - São Paulo/SP, Brazil.

IV Department of Infectious Diseases - Hospital das Clínicas da Faculdade de Medicina da Universidade de São Paulo - São Paulo/SP, Brazil.

v Department of Pathology - Hospital das Clínicas da Faculdade de Medicina da Universidade de São Paulo - São Paulo/SP, Brazil.

${ }^{\mathrm{V}}$ Instituto da Criança - Hospital das Clínicas da Faculdade de Medicina da Universidade de São Paulo - São Paulo/SP, Brazil.
}

weeks, the swine-origin influenza virus (S-OIV) H1N1 spread worldwide, constituting a pandemic, as defined by the World Health Organization. ${ }^{4}$ The novel H1N1 virus has distinct molecular properties of human, avian, and swine influenza, resulting from antigenic drift, which is the main cause of the seasonal epidemic of swine flu. ${ }^{4}$

As of September 13, 2009, the S-OIV caused over than 296.471 virologically confirmed human cases and at least 3.486 deaths in countries worldwide..$^{5}$ Almost five months

\footnotetext{
VII Hospital das Clínicas da Faculdade de Medicina da Universidade de São Paulo - São Paulo/SP, Brazil.

viI Hospital das Clínicas da Faculdade de Medicina da Universidade de São Paulo - São Paulo/SP, Brazil.

${ }^{\mathrm{Ix}}$ Department of Internal Medicine - Hospital das Clínicas da Faculdade de Medicina da Universidade de São Paulo - São Paulo/SP, Brazil.

${ }^{x}$ Faculdade de Medicina da Universidade de São Paulo - São Paulo/SP, Brazil.

${ }^{\mathrm{XI}}$ Hospital das Clínicas da Faculdade de Medicina da Universidade de São

Paulo - São Paulo/SP, Brazil.

Email: diretoria.clinica@hcnet.usp.br

Tel.: 55113069.6431

Received for publication on September 22, 2009.

Accepted for publication on September 29, 2009.
} 
after the description of the first cases, the pandemic S-OIV infection continues to spread globally, presents a high rate of transmission among humans, and can lead to serious complications and mortality. The purpose of this guideline is to review the evidence concerning diagnosis, prevention, and treatment of S-OIV infection. In addition, we emphasize the Hospital das Clínicas' plan for the management of the pandemic novel influenza A (H1N1). This report is an initiative from the "Cabinet Crisis" - a group of healthcare professionals at the Hospital das Clínicas da Faculdade de Medicina da Unversidade de São Paulo who continuously evaluate the "bundles" for control of S-OIV infection, meaning the groups of interventions and advertisements, to obtain better outcomes in the management of this disease.

\section{HISTORICAL ASPECTS}

An estimated $58 \%$ of the 1407 human pathogens are zoonotic, which means that they normally occur in animals but can also infect humans. ${ }^{6}$ The ability of a microorganism to cross the species barrier in association with a high transmissibility rate between humans may result in epidemics. The novel influenza A (H1N1) virus, which is responsible for the current pandemic, is derived from two unrelated swine viruses, one of which is a derivative of the 1918 human virus. ${ }^{3}$ The notorious 1918 pandemic of influenza A (H1N1), the Spanish flu, was derived from an avian source and caused 50 million deaths. ${ }^{6}$ Some authors proposed that the virus resided in an avian reservoir and affected humans either directly upon exposure to birds or through an intermediate host. ${ }^{7}$ As the 1918 influenza virus can replicate and cause disease in swine, scientists believe that it has continued to circulate in swine and this fact would facilitate the genetic reassortment between different influenza virus strains. ${ }^{8}$

A practical way to think about influenza A events over the past 91 years is to recognize that we are living in a pandemic era that began in 1918. The novel H1N1 virus associated with the ongoing 2009 pandemic is a fourth-generation descendant of the 1918 virus. The complex evolutionary history of this virus combines unique structural properties and genetic mixing among human viruses and avian and swine-adapted influenza viruses. ${ }^{9}$ Two features of the influenza virus explain its ability to cause widespread disease. One is the high error rate during genomic replication. ${ }^{9,10}$ The other is the segmented influenza virus genome, which allows reassortment between different viral strains..$^{9,10}$ Because of this continual change phenomenon, a seemingly endless variety of new viruses with potentially new properties are continuously being engineered. In contrast, this new virus is not only infecting humans and causing some disease, but it is also being transmitted efficiently from human to human.

\section{EPIDEMIOLOGY}

The pandemic novel influenza A (H1N1) infection was considered as widespread in Brazil on July $16 .{ }^{11}$ Since then, the Ministry of Health in Brazil, as suggested by the World Health Organization, has maintained a continuous epidemiologic vigilance of cases of acute respiratory syndrome (ARS). The strategy of vigilance considers any persons with flu syndrome as potential cases of influenza A (H1N1) and designates these individuals as presenting acute respiratory syndrome patients with cough, dyspnea, and fever.

Until now, 46.810 cases of ARS were reported notified in Brazil. ${ }^{12}$ Of these, 9.249 (20\%) patients presented infection with S-OIV or influenza A (H1N1). Seasonal influenza A infection was confirmed in $1.152(2.5 \%)$ patients. ${ }^{11}$

The observed age distribution is unusual and differs from seasonal influenza, being skewed towards younger age groups. There is a marked underrepresentation of infections in persons over 65 years of age, who make up only $2 \%$ of the reported cases. In Brazil, among the reported cases, the affected individuals tend to be young, with a median age of 26 years. Most patients are 15-49 years of age. Considering the gender distribution, $57.5 \%$ of the confirmed cases of novel virus influenza A (H1N1) occur in women. ${ }^{11,12}$.

Among these 9.249 confirmed cases in Brazil, 899 deaths are reported with mortality rate of $0,47 /$ per 100.000 inhabitants. ${ }^{11}$ All Brazilian states have reported cases of S-OIV infection, with the exception of Sergipe. Most cases and deaths are concentrated in São Paulo, but major mortality rate was observed in Paraná (2,08/ 100.000 inhabitants).

As of September 12, 2009, 13.069 cases of ARS were registered in São Paulo and 3.733 are due to novel influenza A (H1N1) infection. ${ }^{11}$ São Paulo state registers $40.3 \%$ (3.733 of 9.249) of all confirmed cases from Brazil, the majority identified in the city.

The Hospital das Clínicas of Faculdade de Medicina da Universidade de São Paulo (HC-FMUSP) is the largest tertiary health care hospital in Brazil, with 6 medical institutes and other associated hospitals, and is a reference center for H1N1 cases in São Paulo. Three months after the report of the first case of novel H1N1 infection in Brazil, the Hospital das Clínicas has accumulated experience with about 1500 cases registered and 472 confirmed with a low lethality rate $(7.14 \%)$.

The management of this disease requires specific knowledge and the expertise to provide an adequate diagnosis and treatment of patients. With the goal of obtaining better outcomes in diseased patients, the Hospital Council established a "Cabinet Crisis" to continuously 
obtain information from Health Organs, Epidemiological Surveillance Systems and from literature regarding epidemiological data and clinical presentations of S-OIV infection and to provide an adequate structure for the care of patients.

\section{PATHOGENESIS}

Influenza $\mathrm{A}, \mathrm{B}$, and $\mathrm{C}$ are RNA viruses of the Ortomyxoviridae family and cause both pandemic and seasonal disease in humans. ${ }^{14}$ Influenza A viruses are enveloped, single-stranded RNA viruses with a segmented genome. They are categorized into subtypes on the basis of the antigenic properties of the hemagglutinin (HA) and neuraminidase (NA) glycoproteins on the surface of the virus. ${ }^{14}$ The HA glycoprotein mediates attachment and entry of the virus on the cell surface and is the main target for immunity by neutralizing antibodies. The NA glycoprotein allows the spread of the virus by cleaving the glycosidic linkages to sialic acid on host cells and on the surface of the virus. ${ }^{15}$ Influenza A viruses are characterized according to their pathogenicity, which results in severe disease and death in different species. This S-OIV results from frequent antigenic changes (i.e., antigenic drift) due to point mutations and recombination events that occur during viral replication. ${ }^{15}$ The novel influenza A (H1N1) virus is not a new subtype, but because the large majority of humans appear to have no pre-existing antibodies to this virus, a substantial potential for widespread infection exists. ${ }^{14,15}$

The novel influenza A (H1N1) virus has distinct properties that enable it to cause disease in both swine and humans and confers high rates of transmissibility among humans. The pathogenesis of human infection due to S-OIV is poorly understood, but appears to involve two phenomena: a) direct cytotoxic viral damage and b) a cytokine storm, resulting from the inflammatory response to viral infection. ${ }^{16,17}$ The interaction between host and virus may result in different forms of disease, depending on the viral load and the inflammatory response. In patients with co-morbidities, host mechanisms of defense may be defective and such patients can present an altered innate immune response. In the most severe cases, co-infection with other viruses and bacteria (Streptococcus pneumoniae, Haemophilus influenza, and Staphylococcus aureus) can occur contributing to the high rates of mortality. ${ }^{18}$

There is no evidence to date suggesting that the virus disseminates any differently from other human influenza viruses, i.e., by droplets from coughing and sneezing and direct and indirect contact with respiratory secretions from infected persons. ${ }^{19}$ An individual may sometimes become infected by touching something contaminated with flu viruses and then touching his or her mouth or nose. ${ }^{19}$ There is no evidence to suggest unusual transmission routes for influenza, and there is no reason to suggest transmission via food. Patients may be contagious from one day before developing symptoms to up to 7 days after they get sick. ${ }^{19,20}$ Children and persons with deficient immunity might be contagious for longer periods of time..$^{20}$

\section{CLINICAL FEATURES}

Human infection with the novel virus influenza A (H1N1) is characterized by a variable clinical presentation. We can describe a spectrum of disease presentations: the asymptomatic form, "flu-like syndrome", and the severe form with acute respiratory distress syndrome leading to death (Figure 1). ${ }^{21}$ The majority of patients present the "flu-like syndrome" with fever, myalgia, sore throat, arthralgia, cough, headache, chills, and fatigue. ${ }^{22,23}$ Fever is the most frequent symptom and usually lasts for three days. Respiratory symptoms generally disappear three or four days after the fever ends. Diarrhea, emesis, and weakness can be present in a significant number of cases. ${ }^{22,23}$

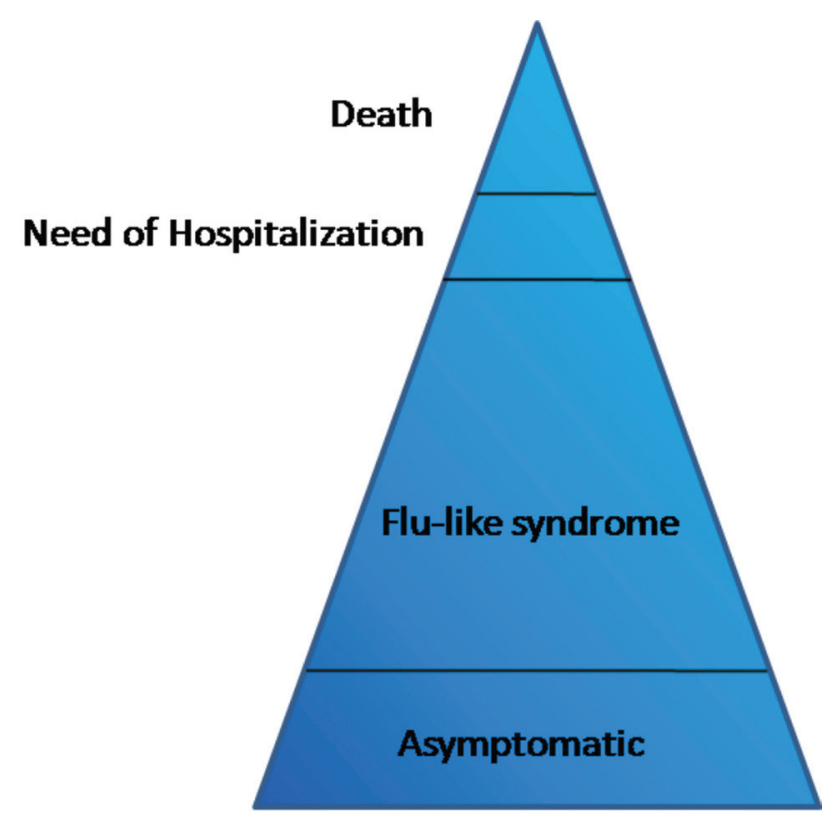

Figure 1 - Spectrum of novel influenza A (H1N1) infection

Despite the fact that in most patients the disease has a benign evolution and a limited duration, some patients may present respiratory failure, rapidly developing acute respiratory distress syndrome..$^{24,25}$ Published data describe systemic disease and complications due to S-OIV infection such as:22,23

a. Worsening of previous existing disease

b. Sinusitis, otitis, asthma 
c. Pneumonia, acute lung injury, respiratory failure

d. Pericarditis, myocarditis

e. Myositis, rhabdomyolysis

f. Acute renal failure due to acute tubular necrosis

g. Encephalitis, seizures

h. Systemic inflammatory response syndrome

i. Multiple organ failure

j. Death

The reported cases reveal that about $70 \%$ of patients who die or present severe forms of the disease have underlying conditions. ${ }^{22,23,24,25,26,27}$ Risk groups for hospitalization and severe disease due to S-OIV infection are:

a. Individuals with underlying chronic diseases: data show that most patients hospitalized due to the need for care present co-morbidities, such as: asthma, chronic obstructive airways disease, diabetes, immunocompromise, chronic cardiovascular disease, chronic renal failure, epilepsy, obesity, and cancer. ${ }^{22,23,24}$

b. Pregnant women: studies report that pregnant women infected with S-OIV have a four to five times greater chance of being hospitalized than healthy pregnant women and present more severe forms of the disease..$^{25,26}$

c. Young children: children under two years of age present high rates of hospitalization and death. ${ }^{27}$

d. Older individuals: persons 65 years and older have a high likelihood of needing hospital care and exhibit a high case fatality rate. ${ }^{23,24}$

From these analyses we can describe a list of risk groups, i.e., groups that experience more severe infections than the general population (Figure 2).

Pregnant women have a potential for complicated disease. For that, in Hospital das Clínicas, there is a specific protocol of care for this group, which include hospital

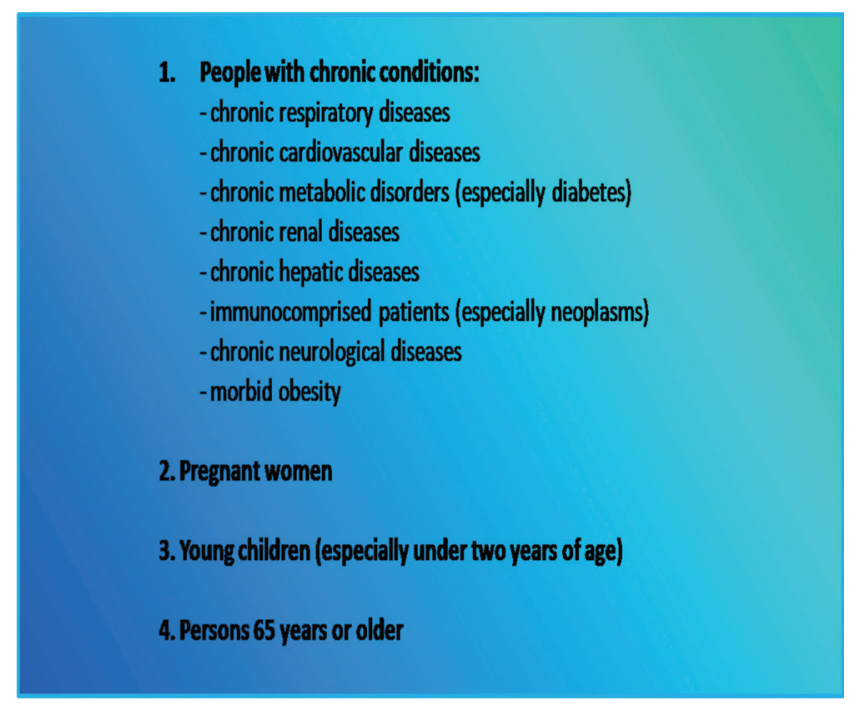

Figure 2 - Risk groups for S-OIV infection admission in suspected or confirmed cases with clinical complications and a careful vigilance system for mild forms of disease with home treatment.

\subsection{Hospital admission}

To date, most human cases of new influenza A (H1N1) virus infection have exhibited an uncomplicated illness of limited duration. Hospitalization or antiviral therapy is therefore not likely to be required for most patients. Supportive care includes antipyretics, such as dypirone or acetaminophen for fever or pain, and fluid rehydration that can be provided as needed. ${ }^{22}$

The specific risk factors that predict an increased risk of progressive disease are incompletely understood. Clinicians and caregivers should watch for signs of possible clinical deterioration (for example, difficulty breathing, chest pain, coughing up colored sputum, dyspnea, altered level of consciousness, and confusion) and refer immediately such patients to the hospital. Clinicians should also take into account any underlying co-morbidities, the already described risk groups (such as immunocompromising conditions, preexisting chronic lung or cardiovascular disease, diabetes, pregnancy, and young age).

Patients who present one or more of the following signs and symptoms must be hospitalized in an intensive care unit:

a) Hemodynamic instability

b) Acute respiratory failure

c) Extensive lung compromise on chest X-ray

d) Severe hypoxemia

e) $\mathrm{An} \mathrm{PO} 2 / \mathrm{FiO} 2<300$, characteristic of acute lung injury

f) Compromise of other organs: acute renal failure, myositis, encephalitis, and other

g) Organ dysfunction

\subsection{Intensive care:}

5.2.1 Ventilatory support: until now, there has been no unique, definite pattern of lung disease. Patients who present serious hypoxemia may present different forms of lung damage. ${ }^{23,24}$ Most patients present diffuse alveolar damage, but localized disease, bronchiolitis, lobar pneumonia, and pleural effusion may be present. Ventilator support indications will then depend on the clinical condition of the patients, evaluated through signs, symptoms, and laboratory analysis (including arterial gas).

- Non-invasive ventilation (NIV): despite the theoretical risk of aerosol production with this modality, we recommend NIV in patients with hypoxemia due to the reduced rates of orotracheal intubation. Indications for and limitations of this method in patients with S-OIV infection 
are the same as those for patients with respiratory failure due to other etiologies. ${ }^{28}$ NIV should be used in patients without hemodynamic instability or consciousness alterations. ${ }^{28,29}$ The preferred modality is the BiPAP, with inspiratory pressure (IPAP) and expiratory pressure (EPAP) adjusted independently. After selecting and fitting the mask, the recommended initial settings are IPAP $=8-12$ $\mathrm{cmH}_{2} \mathrm{O}$ and EPAP $=3-5 \mathrm{cmH}_{2} \mathrm{O}$. The IPAP is increased gradually as tolerated, with the therapeutics goals of dyspnea relief, good patient-ventilator synchrony, and improved gas exchange. The EPAP may be increased as needed for alveolar recruitment.

- Invasive ventilation:

- Treatment of ARDS associated with new influenza A (H1N1) virus infection should be based on published evidence-based guidelines for sepsis-associated ARDS. ${ }^{29,30}$ Lung-protective mechanical ventilation strategies should be used. The rationale is not to cause damage of nonaffected areas. We recommend the following therapy:

a) Ventilatory mode: most ARDS patients are ventilated using conventional volume-cycled positivepressure ventilators. Most studies using low tidal volume for ARDS employed this mode. ${ }^{29,30}$ However, no differences in outcomes are detected if pressurecontrolled ventilation is chosen, since the low tidal volume strategy is reached.

b) Oxygen: treatment of hypoxemia in ARDS induced by $\mathrm{H} 1 \mathrm{~N} 1$ virus is almost always initiated using $100 \%$ oxygen $\left(\mathrm{FIO}_{2}=1.0\right)$, and the concentration of $\mathrm{O}_{2}$ is reduced with the goal of maintaining a $\mathrm{PaO}_{2}$ greater than $60 \mathrm{mmHg}$ (arterial $\mathrm{O}_{2}$ saturation of about $90 \%$ ). The $\mathrm{FIO}_{2}$ should be lowered to less than 0.5 as soon as possible to reduce the risk of lung damage due to oxygen toxicity.

c) Positive End-Expiratory Pressure (PEEP): Positive end-expiratory pressure works by counteracting the tendency toward alveoli collapse during pulmonary edema, low lung volume, and loss of surfactant. ${ }^{31}$ In ARDS, the majority of the lung is atelectatic. ${ }^{29}$ PEEP recruits partially collapsed areas, improving gas exchange. ${ }^{31}$ However, in some cases it is associated with barotrauma, pneumothorax, lung injury, inflammation, a cardiac output decrease, and shock. ${ }^{32}$ Consequently, we recommend a PEEP level between 5 and $12 \mathrm{~cm} \mathrm{H}_{2} \mathrm{O}$ in most patients, and we can adjust the PEEP levels using a combination of the PV curve, the response of arterial blood gases, the hypothetical maximum and minimum PEEP values, and the hemodynamic response.

d) Low-tidal-volume strategy: the most important development in the management of ARDS is that mechanical ventilation with a lower tidal volume than previously used is associated with an improved clinical outcome. ${ }^{29,30}$ This type of ventilation has been termed as the low-tidal volume or lung-protective strategy. The best risk:benefit ratio would be gained with a tidal volume of $6 \mathrm{ml} / \mathrm{Kg}$ or less, to reach a target plateau pressure of less than $30 \mathrm{~cm} \mathrm{H}_{2} \mathrm{O} .{ }^{30}$

e) Recruitment maneuvers and the prone position: recruitment maneuvers and the prone position must be reserved for refractory hypoxemia, as in other cases of ARDS. ${ }^{33,34}$

5.2.2 Hemodynamic support: Patients admitted to the intensive care unit with S-OIV infection and ARDS may present shock. It is of main importance to maintain hemodynamic goals in these patients to avoid organ failure. Fluid management in this population should be performed carefully. Current evidence indicates that a net negative balance is desirable in ARDS. ${ }^{35}$ However, in these patients, hypovolemia must be avoided. Therefore, we recommend dynamic evaluation of the fluid status and a more conservative strategy for fluid replacement. In some cases, albumin associated with furosemide may offer benefit in the net balance. ${ }^{35,36}$

\section{Hemodynamic goals:}

- Mean arterial pressure $>65 \mathrm{mmHg}$

- $\mathrm{SVO}_{2}>70 \%$

- Lactate $<2 \mathrm{mmol} / \mathrm{L}$

- Diuresis higher than $1 \mathrm{ml} / \mathrm{Kg} / \mathrm{h}$

For optimal tissue perfusion and to obtain adequate arterial pressure, it is often necessary to use vasopressors and inotropics. We suggest norepinephrine as the first-line vasopressor and dobutamine as the inotropic. Vasopressin should be reserved for refractory shock. ${ }^{37}$

5.2.3 Renal support: acute renal failure has been observed in patients with S-OIV infection, especially in cases presenting shock. ${ }^{22}$ The etiology of acute renal failure is usually acute tubular necrosis, and in such cases renal replacement therapy may be needed.

5.2.4 Corticosteroids: controversy exists as to whether we should use high-dose corticosteroids in ARDS due to S-OIV infection. ${ }^{38}$ The positive effect would be a reduction of the inflammatory lung injury, potentially resulting in a better PO2/FIO2 ratio and less intubation, as in ARDS of other etiologies. ${ }^{39}$ The adverse events in influenza virusinfected patients would be higher rates of opportunistic infection and, possibly, prolonged viral replication. We 
do not have pathology data for H1N1 infection to guide the choice of therapy. So, we recommend the use of methylprednisolone ( $2 \mathrm{mg} / \mathrm{Kg}$ per day) just in cases of ARDS that do not response to initial measures.

Low doses of corticosteroids (hydrocortisone $50 \mathrm{mg}$ IV four times per day) may be considered for patients in septic shock who require vasopressors and have suspected adrenal insufficiency.

5.2.5 Antibiotics: antibiotic chemoprophylaxis should not be used. When pneumonia is present, treatment with antibiotics should follow the recommendations from published guidelines. However, seasonal influenza and past influenza pandemics have been associated with an increased risk of secondary Staphylococcus aureus infections, which may be severe, progress rapidly, have necrotizing effects, and, in some areas, may be caused by methicillinresistant strains. ${ }^{40}$ The results of microbiological studies, wherever possible, should be used to guide antibiotic usage for suspected bacterial coinfection in patients infected with the new influenza A (H1N1) virus. Several patients worldwide have developed community pneumoniae due to Streptococcus pneumoniae and Haemophilus influenza and ventilator-associated pneumonia or hospital-acquired pneumonia caused by typical nosocomial pathogens. ${ }^{41}$

5.2.6 Glycemic control: tight glucose control $(<140 \mathrm{mg} /$ dL) must be achieved in critically ill patients, according to the local protocol. This measure is associated with a decrease of morbidity and mortality in critical patients. ${ }^{42}$

5.2.7 Thromboembolic prophylaxis: patients infected with S-OIV should receive mechanical thromboprophylaxis and pharmacological if possible because, as critically ill patients with co-morbidities, they present a high risk for thromboembolic events. In a series of cases from Michigan, of 10 patients with S-OIV infection, five had a pulmonary embolism, although the higher incidence of thrombosis could be explained because seven were extremely obese (body mass index $>40$ ). ${ }^{43}$

\section{DIAGNOSIS}

Laboratory confirmation of the novel influenza A (H1N1) virus, especially at the beginning of a new community outbreak, or for unusual cases, has important implications for case management, consideration of antiviral treatment options, and avoidance of the inappropriate use of

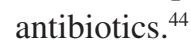

Reverse transcriptase-polymerase chain reaction (RTPCR) will provide the most timely and sensitive evidence of infection with the novel influenza A (H1N1) virus. ${ }^{44,45}$ Real-time RT-PCR is available in reference centers around the world. ${ }^{46}$ Samples for laboratory tests should be obtained from the deep nasal passages (nasal swab), nasopharynx (nasopharyngeal swab), or the bronchial aspirate if available. ${ }^{47}$ Upper respiratory tract sampling using a combination of nasal or nasopharyngeal and a throat swab is advised and may facilitate virus detection. It is not yet known which clinical specimen provides the best diagnostic yield for this specific infection. ${ }^{48}$ Specimen collection should be carried out with precautions since the procedure may expose the collector to respiratory secretions from infected patients.

The real-time test through polymerase chain reaction, includes the use of specific primers and probes to diagnose S-OIV infection. ${ }^{46}$ The set of influenza primers and probes was created to detect:

(a) Seasonal influenza A virus

(b) Swine-origin influenza A virus

(c) Novel virus influenza A (H1N1)

Currently, the data show that this method has a sensitivity of $99.3 \%$ and a specificity of $92.3 \%$ for the diagnosis of infection due to novel virus influenza A (H1N1). ${ }^{46}$ We recommend the following types of cases to be submitted for the test:

a) patients who require hospitalization

b) patients with risk factors for severe forms of disease

c) patients in an individualized protocol - according to the clinical judgment

No validated rapid bedside diagnostic test is presently available to detect novel influenza A (H1N1) virus infection. As part of the HC "bundles" for control of novel H1N1 infection, a real-time RT-PCR is available for patients and workers who fill criteria to be tested.

\section{TREATMENT AND PROPHYLAXIS}

The novel influenza A (H1N1) virus is currently susceptible to the antiviral medications known as neuraminidase inhibitors (NAIs), specifically oseltamivir and zanamivir. ${ }^{49,50}$ The virus is resistant to the adamantane medications amantadine or rimantadine. ${ }^{49}$ Clinical efficacy data on antiviral treatment are not yet available. Based on its in vitro susceptibility patterns and the clinical experiences derived from seasonal and avian influenza infection, early administration of NAIs might reduce the severity and duration of illness caused by the novel H1N1 virus infection and might also help to prevent progression to severe disease and death. ${ }^{51}$ Only sporadic cases of oseltamivir-resistant 2009 influenza A (H1N1) viruses have been detected 
Table 1 - Recommended antiviral treatment and prophylaxis for novel influenza A (H1N1) infection

\begin{tabular}{llll}
\hline & & $\begin{array}{l}\text { Treatment } \\
\text { Oseltamivir }\end{array}$ & $\begin{array}{l}\text { Chemoprophylaxis } \\
\text { Oseltamivir }\end{array}$ \\
\hline Adults & & 75 -mg capsule twice per day for 5 days & 75 -mg capsule once per day for 10 days \\
Children $\geq 12$ months & $15 \mathrm{~kg}$ or less & $60 \mathrm{mg}$ per day divided into 2 doses & $30 \mathrm{mg}$ once per day \\
& $16-23 \mathrm{~kg}$ & $90 \mathrm{mg}$ per day divided into 2 doses & $45 \mathrm{mg}$ once per day \\
& $24-40 \mathrm{~kg}$ & $120 \mathrm{mg}$ per day divided into 2 doses & $60 \mathrm{mg}$ once per day \\
& $>40 \mathrm{~kg}$ & $150 \mathrm{mg}$ per day divided into 2 doses & $75 \mathrm{mg}$ once per day \\
\hline
\end{tabular}

worldwide, including nine cases in the United States. ${ }^{52}$ Eight of nine patients had a documented exposure to oseltamivir through either treatment or prophylaxis. ${ }^{52}$

Clinical judgment is an important factor in the treatment decision. People with suspected novel H1N1 influenza who present with an uncomplicated febrile illness typically do not require treatment unless they are at higher risk for influenza complications, and in areas with limited antiviral availability, local public health authorities might provide guidance about prioritizing treatment within groups at higher risk. ${ }^{53}$

Antiviral therapy may be beneficial, especially for the following groups: ${ }^{54}$

1. All hospitalized patients with confirmed, probable, or suspected novel influenza (H1N1).

2. Patients who are at a higher risk for complications (listed above).

If used, antiviral treatment should ideally be initiated early, as soon as possible, but it may also be used at any stage of the active disease when ongoing viral replication is anticipated or documented. Evidence for the benefits of antiviral treatment in studies of seasonal influenza is highest when treatment is started within 48 hours of the onset of illness. ${ }^{55}$ However, studies investigating oseltamivir treatment of hospitalized patients have indicated a benefit, including reductions of mortality or duration of hospital stay, even for patients whose treatment was initiated after 48 hours. $^{56}$

There are important pharmacological differences to consider when choosing NAIs for treatment. Oseltamivir is administered orally and provides a higher systemic level. ${ }^{57}$ Zanamivir is delivered by oral inhalation, with low systemic absorption. ${ }^{57}$ Oseltamivir is the recommended treatment for lower respiratory tract complications. ${ }^{57}$ The recommended treatment duration is five days. In Brazil, oseltamivir is used for the treatment and prophylaxis of S-OIV infection (Tables 1, 2 and 3).

Rare neuropsychiatric symptoms, such as confusion or abnormal behavior, have occurred after beginning treatment for seasonal influenza with oseltamivir, particularly in
Table 2 - Recommended antiviral treatment for children younger than 1 year using oseltamivir

\begin{tabular}{ll}
\hline Age & Recommended treatment for 5 days \\
\hline$<3$ months & $12 \mathrm{mg}$ twice daily \\
$3-5$ months & $20 \mathrm{mg}$ twice daily \\
$6-11$ months & $25 \mathrm{mg}$ twice daily \\
\hline
\end{tabular}

Table 3 - Recommended antiviral chemoprophylaxis for children younger than 1 year using oseltamivir

\begin{tabular}{ll}
\hline Age & Recommended prophylaxis for 10 days \\
\hline$<3$ months & $\begin{array}{l}\text { Not recommended unless the situation is judged as } \\
\text { critical }\end{array}$ \\
$3-5$ months & $20 \mathrm{mg}$ once daily \\
6-11 months & $25 \mathrm{mg}$ once daily \\
\hline
\end{tabular}

children, but the contribution of oseltamivir to these events remains unknown. ${ }^{58}$

Post-exposure antiviral chemoprophylaxis with either oseltamivir or zanamivir for 10 days can be considered for the following situations: ${ }^{59}$

1. Close contact of cases (confirmed, probable, or suspected) who are at a high risk for influenza complications

2. Health care personnel, public health workers, or first responders who have had a recognized, unprotected close contact exposure to a person with novel (H1N1) influenza virus infection during the patient's infectious period.

In patients presenting renal failure, with a creatinine clearance between 10 and $30 \mathrm{ml} / \mathrm{min} / \mathrm{m} 2$, a $50 \%$ dosage reduction of oseltamivir is recommended. ${ }^{60}$ There are no data available on the ideal dosage during renal replacement therapy. Patients with hepatic failure do not require dosage correction. ${ }^{60}$

Zanamivir is indicated for the treatment of influenza in adults and children ( $>5$ years) ${ }^{57}$ The recommended dose for treatment of adults and children older than 5 years of age is two inhalations ( 2 x $5 \mathrm{mg}$ ) twice daily for 5 days. 
Inhaled zanamivir has been temporally associated with bronchospasm, and patients with preexisting airway disease appear to be at an increased risk for this severe adverse reaction. ${ }^{57}$

\section{Available products in Brazil:}

(a) Tamiflu ${ }^{\circledR}$ Roche - 75-mg capsule and 52-ml oral suspension $(12 \mathrm{mg} / \mathrm{ml})$

(b) Oseltamivir Farmanguinhos - 75-mg capsule

(c) Oseltamivir HC - 50-ml oral suspension (15 mg/ml)

\section{PREVENTION}

Until now, no vaccine has been commercially available to protect against novel $\mathrm{H} 1 \mathrm{~N} 1$ virus, although there are everyday actions known to prevent the spread of infection, such as: ${ }^{61}$

- Wash your hands often with soap and water. Alcoholbased hand cleaners are also effective.

- Try to avoid close contact with sick people.

- Cover your nose and mouth with a tissue when you cough or sneeze.

- Stay home if you are sick for 7 days after your symptoms begin or until you have been symptom-free for 24 hours.

- Follow public health advice regarding school closures, avoid crowds.

\section{CARE OF PATIENTS WITH CONFIRMED, SUS- PECTED, OR PROBABLE INFECTION WITH THE NOVEL VIRUS INFLUENZA A (H1/N1)}

Health care professionals must use the following personal protective equipment ${ }^{62}$ :

a) A surgical mask when the professional is working at a distance of less than 1 meter from the patients, in procedures without aerosol production.

b) Special clothes to avoid contact with blood and fluids.

c) A N95 mask, protective glasses, and gloves in procedures with aerosol production, such as intubation, secretion manipulation, and autopsies.

\section{HC "BUNDLES" FOR NOVEL INFLUENZA A (H1N1) INFECTION}

As already mentioned, as a reference center for H1N1 infection, the Hospital das Clínicas da Universidade de São Paulo created the "Cabinet Crisis" with the objectives of implementing "bundles" for control of S-OIV infection, a group of interventions to obtain better outcomes in the management of this disease. We adopted some measures to obtain continuous and everyday information on the H1N1 infection, to implement actions to control the pandemics and to evaluate the impact of these interventions such as:

1. Periodical meetings among healthcare professionals from all institutions - directors, professors, epidemiologists, infectologists, intensive care physicians - to discuss new data and information about the disease

2. Continuous local Epidemiologic Surveillance to collect and analyze the data to assess the impact of the virus and determine the groups at an increased risk of complications.

3. Information for all professionals and patients about the infection, symptoms, diagnosis, and prevention.

4. Availability of a real time RT-PCR for novel influenza A (H1N1) virus in admitted patients.

5. Reduction of daily visits of families to the hospital.

6. Implementation of hygienic measures: alcohol-based hand cleaner, gloves, masks.

7. Internet published recommendations on the management of infection (www.hcnet.usp.br)

8. Specific units for the care of patients with suspected or confirmed S-OIV infection including emergency room attending, regular ward and specialized intensive care units.

9. Guidance for the staff and coworkers to limit contact with other people when symptoms are present.

10. Risk groups specialized protocols of care: pregnant women, children, immunocompromised patients, and chronic diseases.

11. Immediate availability of antiviral therapy.

In the last weeks, we could observe a significant reduction in the incidence and mortality of novel influenza $\mathrm{A}$ (H1N1) infection in São Paulo and in Hospital das Clínicas. We suppose that an association of factors contribute to these numbers including a global actions plan, the continuous epidemiologic monitoring and the acquired expertise to diagnosis and adequate treatment of patients. We wish to maintain all the adopted measures in Hospital das Clínicas with the ongoing objective of obtain better outcomes in the management of novel influenza A (H1N1) infection. With the accumulating experience and groups of study, we hope to contribute continuously with information regarding epidemiology, pathogenesis and clinical aspects of this pandemics.

\section{CONCLUSIONS AND PERSPECTIVES}

The 2009 pandemic novel influenza A (H1N1) infection continues to spread globally and displays the complexity of preexisting viruses, which become highly transmissible through genetic mutations and reassortments. In less than 
200 days of known disease in humans, we learned that the replication competence and virulence of the novel H1N1 virus enable it to cause severe clinical presentations and death. As a consequence of this outbreak, the world learned the value of nonpharmacologic interventions, which can save many lives. A vaccine is expected as a potential control measure for the pandemic. ${ }^{63}$ In the Hospital das Clínicas da Universidade de São Paulo, a "Cabinet Crisis" was created to implement a group of interventions to obtain better outcomes in the management of $\mathrm{H} 1 \mathrm{~N} 1$ infection.

In our opinion, to control this pandemic, global actions are required without a geographic barrier. More studies are needed in zoonotic virology to allow a better understanding concerning the pathogenesis and epidemiologic aspects of the new viruses to prevent emergent diseases.

\section{ACKNOWLEDGEMENTS}

Adriana Sayuri Hirota, Werther Brunow de Carvalho, Alberto José da Silva Duarte, Felipe Silva Fittipaldi, Ho Yeh Li, Marcelo Magri, Marcelo Park, Marcelo Zugaib, Pedro Paulo Pereira, Rossana Pulcineli Vieira Francisco, Ruy Pires Neto, Sonia Lucena Cipriano, Vanusa Barbosa Pinto, and Clarisse Machado, and Renata Lobo.

\section{REFERENCES}

1. Update: swine influenza A (H1N1) infections--California and Texas, April 2009. MMWR Morb Mortal Wkly Rep. 2009;58:435-7.

2. Update: novel influenza A (H1N1) virus infection - Mexico, March-May, 2009. MMWR Morb Mortal Wkly Rep. 2009;58:585-9.

3. Swine influenza A (H1N1) infection in two children--Southern California, March-April 2009. MMWR Morb Mortal Wkly Rep. 2009;58:400-2.

4. Dawood FS, Jain S, Finelli L, Shaw MW, Lindstrom S, Garten RJ et al. Emergence of a novel swine-origin influenza A (H1N1) virus in humans. N Engl J Med. 2009;360:2605-15.

5. Pandemic (H1N1) 2009 - ECDC Daily Update. 2009. (Accessed August 24, 2009, at http://www.ecdc.europa.eu/en/healthtopics/ Documents/090821_Influenza_AH1N1_Situation_Report_1700hrs. pdf.)

6. Woolhouse ME, Gowtage-Sequeria S. Host range and emerging and reemerging pathogens. Emerg Infect Dis. 2005;11:1842-47.

7. Peiris JSM, Poon LLM, Guan Yi. Emergence of a novel swine-origin influenza A virus (S-OIV) H1N1 virus in humans. Journal of Clinical Virology. 2009; 45:169-73

8. Morens DM, Taubenberger JK, Fauci AS. The persistent legacy of the 1918 influenza virus. N Engl J Med. 2009;361(3):225-29.

9. Sandrock C, Kelly T. Clinical review: update of avian influenza A infections in humans. Crit Care. 2007;11:209-

10. Kendal AP. Epidemiologic implications of changes in the influenza virus genome. Am J Med. 1987;82:4-14.

11. Brazilian Epidemiologic Report - Influenza A (H1N1). 2009. (Accessed August 24, 2009, at http://portal.saude.gov.br/portal/arquivos/pdf/ informe_influenza_se_32_publicacao_18ago2009.pdf.)

12. Zimmer SM, Burke DS. Historical perspective--Emergence of influenza A (H1N1) viruses. N Engl J Med 2009:361:279-85.

13. Rambaut A, Pybus OG, Nelson MI, Viboud C, Taubenberger JK, Holmes EC. The genomic and epidemiological dynamics of human influenza A virus. Nature. 2008;453:615-19.

14. Garten RJ, Davis CT, Russel CA, Shu B, Lindstrom S, Balish A, et al. Antigenic and genetic characteristics of swine-origin 2009 $\mathrm{A}(\mathrm{H} 1 \mathrm{N1})$ influenza viruses circulating in humans. Science. 2009; 10;325(5937): 197-201.

15. Webster RG, Bean WJ, Gorman OT, Chambers TM, Kawaoka Y. Evolution and ecology of influenza A viruses. Microbiol Rev. 1992;56:152-79.

16. Taubenberger JK, Morens DM. The pathology of influenza virus infections. Annu Rev Pathol. 2008;3:499-522.

17. Heltzer ML, Coffin SE, Maurer K, et al. Immune dysregulation in severe influenza. J Leukoc Biol. 2009;85:1036-43.

18. Morens DM, Taubenberger JK, Fauci AS. Predominant role of bacterial pneumonia as a cause of death in pandemic influenza: implications for pandemic influenza preparedness. J Infect Dis. 2008;198:962-70.
19. Centers for Disease Control and Prevention. Update: novel influenza A (H1N1) virus infection -Worldwide May 6, 2009. MMWR. 2009;58:453-8.

20. Centers for Disease Control and Prevention. Update: novel influenza A (H1N1) virus infection - Worldwide. MMWR. 2009;58:453-8.

21. Centers for Disease Control and Prevention. Outbreak of swine-origin influenza A (H1N1) virus infection - Mexico, March--April 2009. MMWR 2009;58:467-70.

22. ECDC working group on influenza $\mathrm{A}(\mathrm{H} 1 \mathrm{~N} 1) \mathrm{v}$. Preliminary analysis of influenza $\mathrm{A}(\mathrm{H} 1 \mathrm{~N} 1) \mathrm{v}$ individual and aggregated case reports from $\mathrm{EU}$ and EFTA countries. Eurosurveillance 2009, 14(23). Available from: http://www.eurosurveillance.org/ViewArticle.aspx?ArticleId=19238

23. Perez-Padilla R, de la Rosa-Zamboni D, Ponce de Leon S, Hernandez M, Quiñones-Falconi F, Bautista E, et al. Pneumonia and respiratory failure from swine-origin influenza A (H1N1) in Mexico. N Engl J Med. 2009;361:680-89

24. Chowell G, Bertozzi SM, Colchero MA, Lopez-Gatell H, AlpucheAranda C, Hernandez M, Miller MA. Severe respiratory disease concurrent with the circulation of H1N1 influenza. N Engl J Med. 2009;361:674-79.

25. Jamieson DJ, Honein MA, Rasmussen SA, Williams JL, Swerdlow DL, Biggerstaff MS, Lindstrom S, et al. H1N1 2009 influenza virus infection during pregnancy in the USA. Lancet. 2009;374:451-58.

26. Centers for Disease Control and Prevention. Novel influenza A (H1N1) virus infections in three pregnant women-United States, April-May, 2009. MMWR Morb Mortal Wkly Rep. 2009;58: 497-500.

27. Uyeki TM. Influenza diagnosis and treatment in children: a review of studies on clinically useful tests and antiviral treatment for influenza. Pediatr Infect Dis J. 2003;22:164-77.

28. Antonelli M, Conti G, Moro ML, Esquinas A, Gonzalez-Diaz G, Confalonieri $\mathrm{M}$, et al. A comparison of noninvasive positive-pressure ventilation and conventional mechanical ventilation in patients with acute respiratory failure. N Engl J Med. 1998; 339:429-35.

29. Ferguson ND, Frutos-Vivar F, Esteban A, Anzueto A, Alía I, Brower RG, et al. Airway pressures, tidal volumes, and mortality in patients with acute respiratory distress syndrome. Crit Care Med. 2005; 33:21-30.

30. The Acute Respiratory Distress Syndrome Network: Ventilation with lower tidal volumes as compared with traditional tidal volumes for acute lung injury and the acute respiratory distress syndrome. N Engl J Med. 2000; 342:1301-08.

31. Villar J, Kacmarek RM, Pérez-Méndez L, Aguirre-Jaime A, for the ARIES Network: A high PEEP-low tidal volume ventilatory strategy improves outcome in persistent ARDS: A randomized controlled trial. Crit Care Med. 2006; 34:1311-18.

32. Stewart TE, Meade MO, Cook DJ, Granton JT, Hodder RV, Lapinsky $\mathrm{SE}$, et al. Evaluation of a ventilation strategy to prevent barotrauma in patients at high risk for acute respiratory distress syndrome. $\mathrm{N}$ Engl $\mathrm{J}$ Med. 1998;338:355-61. 
33. Gattinoni L, Caironi P, Cressoni M, Chiumello D, Ranieri VM, Quintel $\mathrm{M}$, et al. Lung recruitment in patients with acute respiratory distress syndrome. N Engl J Med. 2006;354:1775-86.

34. Stocker R, Neff T, Stein S, Ecknauer E, Trentz O, Russi E. Prone positioning and low-volume pressure limited ventilation improve survival in patients with severe ARDS. Chest. 1997; 111:1008-17.

35. Dubois MJ, Orellana-Jimenez C, Melot C, De Backer D, Berre J, Leeman $\mathrm{M}$, et al. Albumin administration improves organ function in critically ill hypoalbuminemic patients: A prospective, randomized, controlled, pilot study. Crit Care Med. 2006; 34: 2536-40.

36. Wiedemann HP, Wheeler AP, Bernard GR, Thompson BT, Hayden D, deBoisblanc B, et al. Comparison of two fluid-management strategies in acute lung injury. N Engl J Med. 2006; 354:2564-75.

37. Russell JA, Walley KR, Singer J, Gordon, AC, Hébert PC, Cooper J, et al. Vasopressin versus Norepinephrine Infusion in Patients with Septic Shock. N Engl J Med. 2008; 358(9):877-87.

38. Marik PE, Pastores SM, Annane D, Meduri GU, Sprung CL, Wiebke $\mathrm{A}$, et al. Recommendations for the diagnosis and management of corticosteroid insufficiency in critically ill adult patients: consensus statements from an international task force by the American College of Critical Care Medicine. Crit Care Med. 2008;36:1937-49.

39. Meduri GU, Marik PE, Chrousos GP, Pastores SM, Arlt W, Beishuizen A, et al. Steroid treatment in ARDS: A critical appraisal of the ARDS network trial and the recent literature. Intensive Care Med. 2008; 34:61-9.

40. Hers JF, Masurel N, Mulder J. Bacteriology and histopathology of the respiratory tract and lungs in fatal Asian influenza. Lancet. 1958;2:11413.

41. Louria DB, Blumenfeld HL, Ellis JT, Kilbourne ED, Rogers DE. Studies on influenza in the pandemic of 1957-1958. II. Pulmonary complications of influenza. J Clin Invest. 1959;38:213-65

42. Fahy BG, Sheehy AM and Coursin DB. Glycemic control. Crit Care Med. 2009;37:1769-76.

43. Centers for Disease Control and Prevention. Intensive-Care Patients with severe novel influenza A (H1N1) virus infections - Michigan, June 2009. MMWR 2009;58(27):749-52.

44. Ginocchio CC, Zhang F, Manji R, Arora S, Bornfreund M, Falk L, et al. Evaluation of multiple test methods for the detection of the novel 2009 influenza A (H1N1) during the New York City outbreak. J Clin Virol 2009;45:191-95.

45. Faix DJ, Sherman SS, Waterman SH. Rapid-test sensitivity for novel swine-origin influenza A (H1N1) virus in humans. N Engl J Med. 2009; 13;361(7):728-9.

46. Carr MJ, Gunson R, Maclean A, Coughlan S, Fitzgerald M, Scully M, et al. Journal of Clinical Virology. 2009;45:196-99.

47. Chan KH, Lai ST, Poon LL, Guan Y, Yuen KY, Peiris JS. Analytical sensitivity of rapid influenza antigen detection tests for swine-origin influenza virus (H1N1). J Clin Virol. 2009;45:205-7.

48. Uyeki TM, Prasad R, Vukotich C, Stebbins S, Rinaldo CR, Ferng YH, et al. Low sensitivity of rapid diagnostic test for influenza. Clin Infect Dis. 2009;48(9):e88-e92.
49. Centers for Diseases Control. Interim guidance on antiviral recommendations for patients with novel influenza A (H1N1) virus infection and their close contacts. Atlanta, GA: US Department of Health and Human Services, CDC; 2009. Available at http://www.cdc. gov/h1n1flu/recommendations.htm.

50. Ellis C, McEwen R. Who should receive Tamiflu for swine flu ? BMJ 2009; 6;339:b2698.

51. Tanaka T, Nakajima K, Murashima A, Garcia-Bournissen F, Koren G, Ito S. Safety of neuraminidase inhibitors against novel influenza A (H1N1) in pregnant and breastfeeding women. CMAJ. 2009;7;181(1-2):55-8.

52. Dharan NJ, Gubareva LV, Meyer JJ, Okomo-Adhiambo M, McClinton RC, Marshall SA, et al. Infections with oseltamivir-resistant influenza A(H1N1) virus in the United States. JAMA. 2009;301:1034--41.

53. Wallensten A, Oliver I, Lewis D, Harrison S. Compliance and side effects of prophylactic oseltamivir treatment in a school in South West England. Euro Surveill. 2009;14(30):19285.

54. Rungrotmongkol T, Intharathep $\mathrm{P}$, Malaisree M, Nunthaboot N, Kaiyawet N, Sompornpisut P, et al. Susceptibility of antiviral drugs against 2009 influenza A (H1N1) virus.Biochem Biophys Res Commun. 2009; 31;385(3):390-4.

55. Couzin-Frankel J. Swine flu outbreak. What role for antiviral drugs? Science. 2009; 8;324(5928):705.

56. Poland GA, Jacobson RM, Ovsyannikova IG. Influenza virus resistance to antiviral agents: a plea for rational use.Clin Infect Dis. 2009;48(9):1254-6.

57. CDC. Updated interim recommendations for the use of antiviral medications in the treatment and prevention of influenza for the 2009-2010 season. Atlanta, GA: CDC; September 8, 2009. Available at http:// www.cdc.gov/h1n1flu/recommendations.htm.

58. Uyeki TM. Influenza diagnosis and treatment in children: a review of studies on clinically useful tests and antiviral treatment for influenza. Pediatr Infect Dis J. 2003;22:164--77.

59. Khazeni N, Bravata DM, Holty JE, Uyeki TM, Stave CD, Gould MK. Safety and Efficacy of Extended-Duration Antiviral Chemoprophylaxis Against Pandemic and Seasonal Influenza. Ann Intern Med. 2009 Aug 3. [Epub ahead of print].

60. Robson R, Buttimore A, Lynn K, Brewster M, Ward P. The pharmacokinetics and tolerability of oseltamivir suspension in patients on haemodialysis and continuous ambulatory peritoneal dialysis. Nephrol Dial Transplant. 2006;21(9):2556-62.

61. Lurie N. H1N1 influenza, public health preparedness, and health care reform. N Engl J Med. 2009; 27;361(9):843-5.

62. Azziz-Baumgartner E, Smith N, González-Alvarez R, Daves S, Layton M, Linares N, et al. Influenza Other Respi Viruses. 2009; 3(4):189-96.

63. Greenberg ME, Lai MH, Hartel GF, Wichems CH, Gittleson C, Bennet $\mathrm{J}$, et al. Response after One Dose of a Monovalent Influenza A (H1N1) 2009 Vaccine -- Preliminary Report. N Eng J Med. 2009; Published at www.nejm.org September 10, 2009 (10.1056/NEJMoa0907413). 